


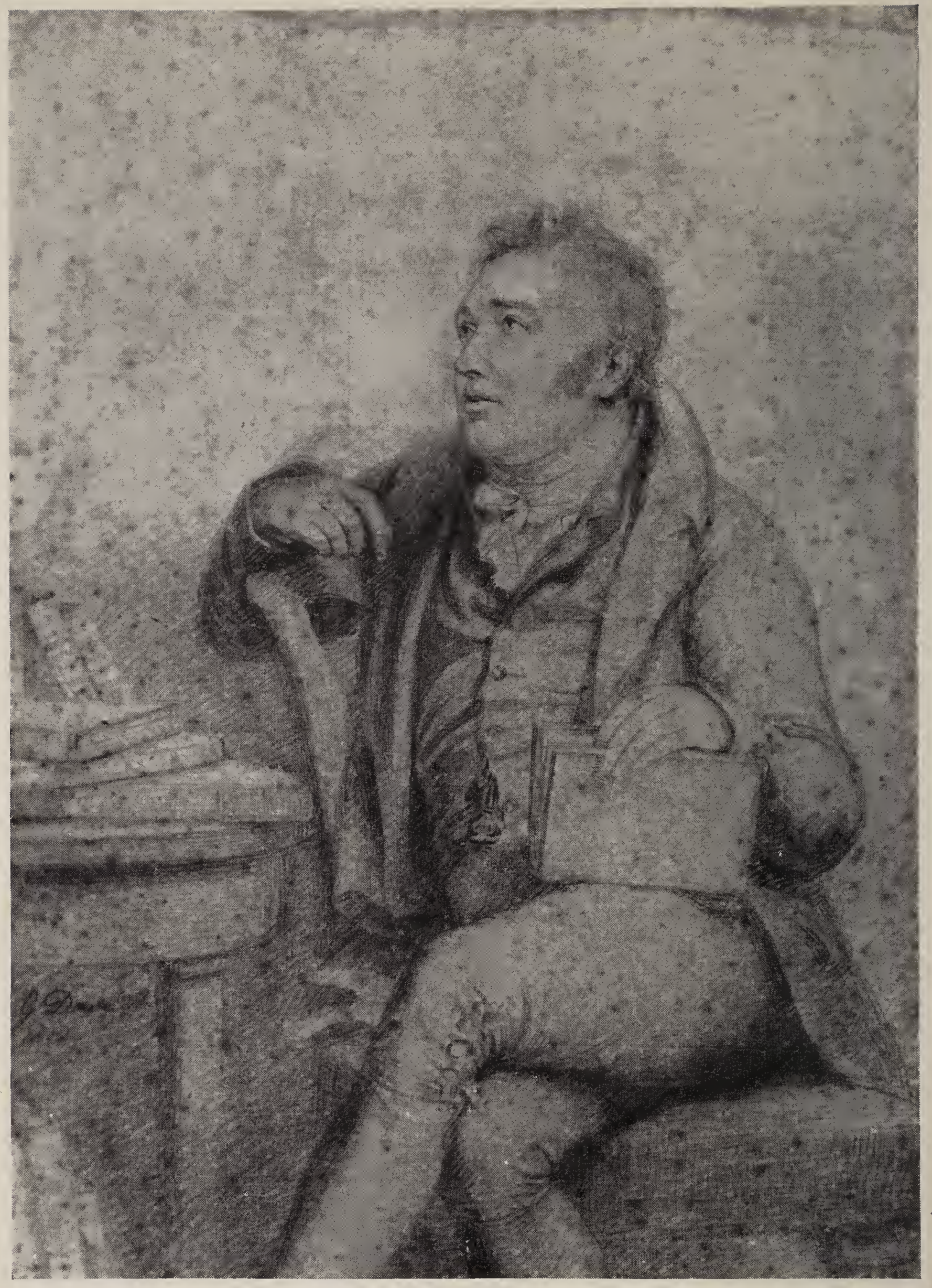

PENCIL DRAWING OF SAMUEL TAYLOR COLERIDGE BY G. DAWES, R.A., DATED 1812 Photo by Henry Wykes, Exeter 


\section{Coleridge the Talker}

A SERIES OF CONTEMPORARY DESCR I P T I O S A N D C OM M E N T S

W I TH A C R I T I C A L I N T R O D U C T I O N B Y R I C H A R D W R A Y M O N D F. H O W E S, Cornell University
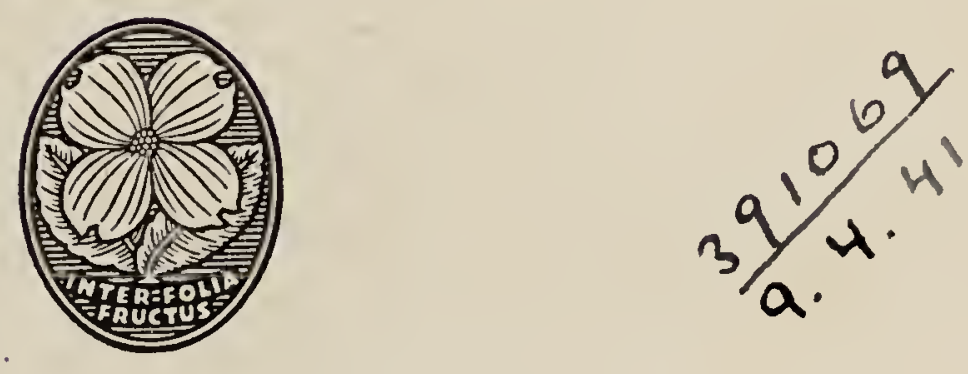

Ithaca, New York : Cornell University Press London : Humphrey Milford : Oxford University Press, 
COP Y R I G H T, 1940, B Y

CORNELL UNIVERSITY

PRINTED IN THE UNITED STATES OFAMERICA

BY THE VAIL-BALLOU PRESS, INC., BINGHAMTON, N. Y.

Designed by Robert Josephy

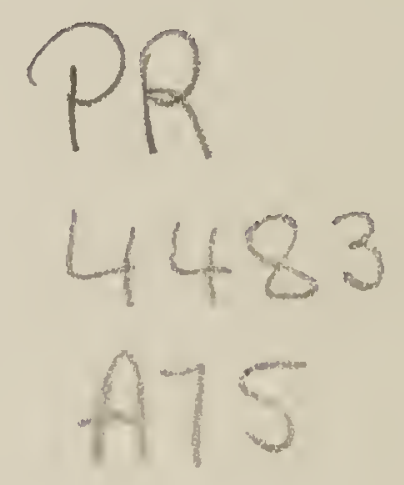


To

JOHN LIVINGSTON LOWES

and

WILLIAM ROY MACKENZIE 
